\title{
Dynamic Behaviour Analysis of Single Stage Planetary Gearbox Under Non-Stationary Operations Using Experimental Test Rig
}

\author{
Haroon Rashid, Hongkun $\mathrm{Li}^{*}$ and Zahid Hussain Hulio \\ School of Mechanical Engineering, Dalian University of Technology, Dalian 116024, China \\ ${ }^{*}$ Corresponding author
}

\begin{abstract}
Planetary gearboxes are mostly used in very hard working situations such as helicopters, wind turbines, heavy trucks, marine vehicle, hybrid cars etc. In order to understand the basic nature of planetary gearbox vibration, this paper includes a vibration and dynamic behavior of single stage planetary gearbox using test rig. Comparison the fault diagnosis of normal planet gear and damaged planet gear, we also calculate the mesh and characteristics frequencies at different operating speed. Based on this assumption, Numerical simulation and vibration signal model of planetary gearbox is obtained. Experimental study is used to verify the model.
\end{abstract}

Keywords-single stage planetary gearbox; vibration signal; fault diagnosis

\section{INTRODUCTION}

Gears are efficient and outstanding power transfer devices. Gears have tremendous load varying ability for which they are manufactured. Planetary gears are mainly useful for transmitting the significant energy with large speed reductions or multiplications. The planetary gears are used in various fields including new generation aircraft, wind turbine, hybrid car and so forth. The research development of planetary gears is essential in order to improve efficiency, compactness, reduce the noise and price. Most of the studies were devoted to static condition where loads and speeds are used as constant. However, the repetitive run up, speed and time-varying loading conditions are generally common in many industrial applications of planetary gears. If the applied torque is excessive, the transmission will bear severe vibrations \& instability. The behavior of load sharing for epicyclic gear set was investigated by Hidaka et al [1]. Kahraman [2] developed load sharing model for planets to predict the errors under quasistatic conditions. Inalpolat [3] carried out a theoretical as well as experimental investigation and observed modulation sidebands in the planetary gear.

For those non-stationary-operations, the variance in speeds will change the configuration of the frequency response: Randal [4] observed that the meshing process prompted vibration amplitude which is adjusted by fluctuating loads. Bartelmus [5] concluded that the transmission-error shape changes with respect to changing load. Chaari [6, 7] investigated the impact of time-varying load \& local-damage on the vibration response implying a model-based technique. Kim [8] studied the dynamic behavior of a planetary gear at different time-varying pressure angles and contact ratios. Similarly, Khabou [9] observed the dynamic behavior of a spur-gear at transient system. At first the spur gear is operated by using an electric motor and then it was driven by four-stroke diesel-engine. Ligata [10] carried out an experimental investigation in order to determine the impact of various kinds of gear stress manufacturing errors and the individual planets loads of $n$ planets. Singh [11] carried out an experimental \& theoretical study to find out the influence of certain key factors on planetary transmissions on gear-stresses and the effect of load sharing in a multi stage planetary-gear-system.

In this paper, the characterization of single stage planetary gear has been carried out. First, a mathematic model is developed, and then variable speed and run up effects are modeled together. The simulated dynamic behavior of the transmission is presented to visualize the non-stationary effects. In last, the correlation of numerical and experimental results is presented.

This paper is organized in following sections: Model description is presented in section II. Characteristic and meshing frequencies of planetary gears are presented in Section III. Similarly, the section IV represents the numerical simulation and experimental validation. Finally, the conclusion is given in section $\mathrm{V}$.

\section{MODEL DESCRIPTION}

A single stage planetary gear box consisting of a middle gear called the sun gear (s), which is connected with two or three intermediate gears called the planet gears $(p)$, the intermediate gears are meshed to a fixed gear which is called ring gear(r) and a carrier(c) all gears are mounted on the carrier plate excepting of ring gear. In a single stage planetary gear transmission system the ring gear is held static during all the experiment. The sun gear is used as input shaft when sun gear revolves the planet gears are rotating around the sun gear and its axis of rotation although the carrier is attached to the output shaft respectively. Sun gear rotates in clock wise direction while the planet gears revolve in anti-clock wise direction and it's vice versa. Finally, the rotating motion of the planetary gears is transmitted to the carrier plate which is responsible for the output of the transmission. Figure I show a single-stage planetary gear model with three planets. 
Planetary gear transmissions generally form part of large transmissions. On behalf of this cause, their bearing housings are unavailable Therefore, the vibrations are typically stately within outer part of the ring gear [12], such as denoted in Figure III. Thus, the model is established to signify this case. The following factors are taken in the progress of the model: (i) vibrations are one which can made in the planet-ring gear mesh processes; (ii) here the only vibrations made in each planet-ring gear mesh process are periodic, with the identical amplitude and have no amplitude variation as well; and in the (iii) vibrations are conveyed to the sensor via the ring gear only which is stated by reference [13].

\section{A. Numerical Model}

Only, rotational motions of the gear bodies are considered. The system's equation of motion for planetary gear with 3 planets is:

$$
M \ddot{q}+c \dot{q}+\left(k(t)+k_{b}\right) q=F(t)
$$

Where $M$ is the mass matrix, $K(t)$ is the stiffness matrix, $k_{b}$ is the bearing matrix and $F(t)$ is the external torque vector applied on the system.

$k(t)$ Can be divided into a mean stiffness matrix $\bar{K}$ and a time varying matrix $(t)$ :

$$
K(t)=\bar{K}+k(t)
$$

$C$ is the proportional damping matrix expressed by:

$$
C=\alpha M+\beta \bar{K}
$$

Where $\alpha$ and $\beta$ are two constants; q refers to the degree of freedom vector

\section{CHARACTERISTICS AND MESHING FREQUENCIES OF PLANETARY GEARS}

\section{A. Meshing Frequency}

When a planet gear completes one relative revolution, it has the same number of meshing teeth with the sun gear and the ring gear. Therefore, the meshing frequency of sun gear to planet gear is equal to the meshing frequency of planet gear to ring gear. Figure I show the planetary gear, if we know the sun gear revolving frequency $f_{s}^{(r)}$ then the meshing frequency $f_{m}$ can be obtained as

$$
f_{m}=f_{c} z_{r}=\left(f_{s}^{(r)}-f_{c}\right) z_{s}
$$

Where $f_{m}$ refers to mesh frequency, the numbers of teeth of the sun gear, the planet gear and ring gear, $Z_{s} Z_{p}$ and $Z_{r}$ respectively. $f c$ is the planet carrier rotating frequency, $f_{s}^{(r)}$ is the sun gear rotating frequency. Thus the planet carrier rotating frequency and sun gear rotating frequency can be calculated as the given below equations:

$$
f_{c}=\frac{f_{s}^{(r)}}{\text { gearratio }}
$$

$$
\begin{gathered}
f_{s}^{(r)}=\frac{\text { revolution }}{\min .} \\
f_{g}=\frac{f_{m}}{z_{g}}
\end{gathered}
$$

\section{B. Characteristic Frequency of Sun Gear}

Characteristic Frequency of Sun Gear with Distributed Fault. Given a distributed fault on a sun gear, the change of meshing condition is in one period when the sun gear completes one relative revolution. Then, the corresponding characteristic frequency of sun gear with distributed fault $\left(f_{s}\right)$ is equal to the ratio of meshing frequency $\left(f_{m}\right)$ to the number of teeth of the sun gear $\left(z_{s}\right)$

$$
f_{s}=\frac{f_{m}}{z_{s}}
$$

\section{Characteristics Frequency of Planet Gear}

The Characteristic Frequency of Planet Gear with Distributed Fault. Given a distributed fault on a planet gear, the change of meshing condition is in one period when the planet gear completes one relative revolution. Thus, the corresponding characteristic frequency of planet gear with distributed fault $\left(f_{p}\right)$ is equal to the ratio of meshing frequency $\left(f_{m}\right)$ to the number of teeth of the planet gear $\left(z_{p}\right)$

$$
f_{p}=\frac{f_{m}}{z_{p}}
$$




\section{Characteristics Frequency of Ring Gear}

Similar to the results from sun gear characteristic frequencies, the characteristic frequency of ring gear with distributed fault $\left(f_{r}\right)$ can be obtained, respectively:

$$
f_{r}=\frac{f_{m}}{z_{r}}
$$

In planetary gearboxes, the ring gear is generally static, while the sun and planet gears as well as the planet carrier revolve. In order to obtain the vibrations, sensors are generally fixed on the casing of the gearbox that is directly attached to the ring gear. In that situation there are three possible transfer ways to obtain the vibration at the planet bearing fault: In path 1 , the vibration starts from the meshing point, goes through the planet gear then ring gear $\rightarrow$ gearbox casing and finally reaches the sensor. In path 2 , the vibration starts from the meshing point, goes through the planet gear with its bearing, planet carrier with its shaft bearing $\rightarrow$ gearbox casing, and finally reaches the sensor. In path 3 , the vibration starts from the meshing point, goes through the sun gear $\rightarrow$ shaft of the sun gear with its bearing $\rightarrow$ gearbox casing, and finally reaches the sensor. There are more items in path 2 and path 3 , which causes serious signal attenuation in comparison with path 1 . Therefore, this paper only considers the signal transmitted through path 1 .

\section{NUMERICAL SIMULATION AND EXPERIMENTAL VALIDATION}

\section{A. Description of Test Rig}

In this section, to verify the numerical results, a test bench is established at the school of mechanical engineering Dalian University of technology in china. In this paper, an experiment is conducted on a single-stage planetary gearbox. The model type of gearbox is NGW11-8, and the gearbox transmission ratio is 6.176 . Other parameters are provided in Table II. The test rig includes a single-stage planetary gearbox, a drive motor, a magnetic powder brake, and a control and data acquisition system, which is shown in Figure II. In the experiment, Dytran $3035 \mathrm{~B}$ sensors are mounted on the top of gearbox in vertical horizontal and axil directions. A tachometer is used to estimate the revolving speed of the carrier. The vibration signals were recorded by the acquisition system "DASP" (Distributive Analysis Stata Package) and with the help of "MATLAB" the data is processed to get amplitude spectra. The data regarding Time-histories is collected from the system and used autopower to obtain frequency-spectra consistent with each averaged time history. Figure IV shows the normal planet gear and the damage one, where the damage gear is artificially seeded.

\section{B. Variable Speed}

An instance of change or fluctuation of speed handled through the rate of recurrence/frequency converter Micro Master 440. Here, this section the dynamic performance of the system offered throughout run up regime. Numerous systems are cause to experience to such iterative regime on their exploitation. That kind of regime is very dangerous since over loads can happen or become overloaded [14]. The Frequency converter instructions linearly the fluctuation of the rotational velocity of the motor, Figure determines the experimentation evolution of the Motor's torque during its run up.

Inside the run up, the time period of gear meshing diminution with the boost or increase of speed and it can be cause of very dangerous for a gear transmission as well. Here it's very significant to describe the powerful performance considering natural frequencies may be excited during this regime and to classify the Eigen Frequencies; an effect test/check a look at is completed. Figure Shows the FRF of the test ring.

For normal planet the data is processed and simulation is carried out under no-load conditions, where the input speed is set to 600 RPM, the simulation time is $10 \mathrm{~s}$, and the average value of the output shaft is 1200 RPM. The sampling frequency is $f_{s}=5100 \mathrm{~Hz}$ and the number of sampling points is 10240 Hz. Similarly, the damage fault frequency can be calculated at $2100 \mathrm{rpm}$, the simulation time is 10 s the sampling frequency is $10240 \mathrm{~Hz}$ and the number of sampling point is $20480 \mathrm{~Hz}$. The reaction of time of the acceleration at the fixed ring is displayed in and it really is well discovered that the vibration is becoming greater with regarding the period/interval meant of directly proportional with the time. It is described by the truth/reality that in run up, the acceleration torque is accelerating with the providing rise to elevated vibration. Furthermore, the greatness of magnitude of oscillation rises inside the period.

\section{Data Analysis}

After a certain time of gearbox running, a piece of vibration signal was collected, and Figure VI shows the spectrum of the signal. The meshing frequency of damage planet gear is $(69.31$ $\& 82.97) \mathrm{Hz}$ ) can be observed which is represented by the highest line in the graph. The small lines correspond to the combination of modulating phenomena caused by the planet carrier rotation and the ring gear error. The other lines represent the planet gear characteristic frequency and the sidebands of modulation phenomena caused by the planet carrier rotation. Therefore, it can be drawn from Figure that the actual sideband distribution in the signal spectrum of planetary gearbox is consistent with the vibration signal model presented.

In Figure VI the time-domain waveforms of the gearbox under normal condition and planet gear damage. Figure III shows the spectra of two signals around the first-order meshing frequency.

It can be perceive/realize that all the statistic metrics of the faulty vibration signal are higher than the ones of the normal signal. The increase of RMS indicates that the existence of fault causes stronger vibration. The Peak Value, Crest Factor, and Kurtosis of fault signal are several times larger than the ones calculated from the normal signal, which means there exist obvious impulses in the time-domain signal. In fact, a comparison of Figures V (a) \& (b) also proves the existence of impulses in gear failure condition.

Through comparison between Figures VI (a) \& (b), it can be observed that the amplitudes of the planet gear characteristic 
frequencies and their corresponding sidebands increase dramatically after planet gear failure. Specifically, obvious spectral lines can be found at the second harmonic of the characteristic frequency of planet gear with distributed fault (i.e., the characteristic frequency of planet gear with two-sided gear tooth fault).

\section{Planet Gear Damage}

The Fourier spectrum in Fig VI (b) reveals that sidebands appear at the frequency locations of with spacing equal to the planet gear characteristics frequency. It is noted that these sidebands signals are bigger than the baseline signal. Some of the peaks are quite prominent at $(69.31 \& 82.97) \mathrm{Hz}$. Although the peaks at are also very prominent, they are not extremely bigger than the base line signal. These features indicate that the planet gear is damaged.

Inside the enclosed spectrum of the elected figure number VI peaks appear at the planet gear damage characteristics frequency as well as and its particular harmonics and their magnitude is generally the superior as compared to the usual planet gear. Into Fourier spectrum, frequency named as an instant frequency of preferred figure peaks also seem on the planet gear features as well as its harmonics, even, however, it is no longer extremely/ precisely eminent. In each extract information/or Demodulated inside spectra, few of other frequency additives as well seem. I.e. Mediate gear rotating frequency of the first level speed-up the gearbox, inside the enclose spectrum, further their summation with perfectly the rotating frequency of the sun gear. This kind of prominent attribute do not mean the First level speed up gearbox defect, due to the fact production's mistake which is incapable of being avoided and can purpose those peaks.

TABLE I. Parameters of Planetary Gear

\begin{tabular}{|c|c|c|}
\hline Power(kw) & Speed (rpm) & Gear ratio \\
\hline 21 & 1200 & 6.176 \\
& & \\
\hline
\end{tabular}

TABLE II. SPECIFICATION OF PLANETARY GEARBOX

\begin{tabular}{|c|c|c|c|}
\hline Gear & sun & Planet(number) & Ring \\
\hline $\begin{array}{c}\text { Tooth } \\
\text { number }\end{array}$ & $\mathbf{1 7}$ & $\mathbf{3 4 ( 3 )}$ & $\mathbf{8 8}$ \\
\hline $\begin{array}{c}\text { Moment } \\
\text { of } \\
\text { inertia }\end{array}$ & $1.35 * 10^{-5}$ & $7.98 * 10^{-4}$ & $4.75 * 10^{-3}$ \\
$\begin{array}{c}\text { Base } \\
\text { diameter }\end{array}$ & $\mathbf{3 1 . 9 5}$ & $\mathbf{6 3 . 9 0}$ & $\mathbf{1 6 5 . 3 8}$ \\
\hline
\end{tabular}

TABLE III. FAULT FREQUENCIES

\begin{tabular}{|c|c|c|c|}
\hline $\begin{array}{c}\text { Revolution } \\
\text { (rpm) }\end{array}$ & 2100 & 1800 & 1500 \\
\hline$f_{s}^{(r)}$ & 35 & 30 & 25 \\
\hline$f_{c}$ & 5.667 & 4.86 & 4.05 \\
\hline$f_{p}$ & 29.33 & 25.1 & 20.95 \\
\hline$f_{s}$ & 14.67 & 12.57 & 10.48 \\
\hline
\end{tabular}

\section{CONCLUSION}

Planetary gearboxes have been widely used in transmission systems of engineering machinery. However, due to its complicated structure, traditional condition monitoring methods for fixed-shaft gearing system are not suitable for planetary gearbox. It is necessary to develop new methods for planetary gearbox condition and fault diagnosis. The main objective of this research is to determine vibration signal model of planetary gear transmission, which helps us to recognize fault phenomena of planetary gearbox and develop reliable fault diagnosis methods. Assume that the whole gearbox reversely revolves around middle of sun gear at a speed of planet gear rotation. Based on the assumptions, the vibration signal model of faulty planetary gearbox is established, and the proposed model provides us with a way to understand different fault phenomena of planetary gearbox. A test rig of planetary gearbox was built, and the vibration data collected from the test rig validated the proposed model. Further, the proposed vibration signal model successfully identified planet gear fault in the gearbox, which may be useful in developing planetary gearbox fault diagnosis methods using the information extracted from vibration signal spectrum.

\section{ACKNOWLEDGMENT}

Give credit to my 'Professor', and I would like to thanks "China Scholarship Council"' for completing this work.

\section{REFERENCES}

[1] Hidaka, T. and Y. Terauchi, Dynamic Behavior of Planetary Gear: 1st Report Load Distribution in Planetary Gear. Bulletin of JSME, 1976. 19(132): p. 690-698.

[2] Kahraman, A., Static load sharing characteristics of transmission planetary gear sets: model and experiment. 1999, SAE Technical Paper.

[3] Inalpolat, M. and A. Kahraman, A theoretical and experimental investigation of modulation sidebands of planetary gear sets. Journal of Sound and Vibration, 2009. 323(3): p. 677-696.

[4] Randall, R., A new method of modeling gear faults. Journal of Mechanical Design, 1982. 104(2): p. 259-267.

[5] Bartelmus, W., et al., Modelling of gearbox dynamics under timevarying nonstationary load for distributed fault detection and diagnosis. European Journal of Mechanics-A/Solids, 2010. 29(4): p. 637-646.

[6] Hammami, A., et al., Dynamic behaviour of two stages planetary gearbox in non-stationary operations. Mechatronic system: theory and application, 2013: p. 23-35.

[7] Chaari, F., et al., Analysis of planetary gear transmission in nonstationary operations. Frontiers of Mechanical Engineering, 2013. 8(1): p. 88-94.

[8] Kim, W., J.Y. Lee, and J. Chung, Dynamic analysis for a planetary gear with time-varying pressure angles and contact ratios. Journal of Sound and Vibration, 2012. 331(4): p. 883-901. 
[9] Khabou, M., et al., Study of a spur gear dynamic behavior in transient regime. Mechanical Systems and Signal Processing, 2011. 25(8): p. 3089-3101.

[10] Ligata, H., A. Kahraman, and A. Singh, An experimental study of the influence of manufacturing errors on the planetary gear stresses and planet load sharing. Journal of Mechanical Design, 2008. 130(4): p. 041701.

[11] Singh, A., A. Kahraman, and H. Ligata, Internal gear strains and load sharing in planetary transmissions: model and experiments. Journal of Mechanical Design, 2008. 130(7): p. 072602.

[12] McFadden, P. and J. Smith, An explanation for the asymmetry of the modulation sidebands about the tooth meshing frequency in epicyclic gear vibration. Proceedings of the Institution of Mechanical Engineers, Part C: Journal of Mechanical Engineering Science, 1985. 199(1): p. 6570.

[13] Vicuña, C.M., Theoretical frequency analysis of vibrations from planetary gearboxes. Forschung im Ingenieurwesen, 2012. 76(1-2): p. $15-31$.

[14] Drago, R. The Effect of Start-Up Load Conditions on Gearbox Performance and Life Failure Analysis, with Supporting Case Study. in American Gear Manufacturers Association Fall Technical Meeting. 2009

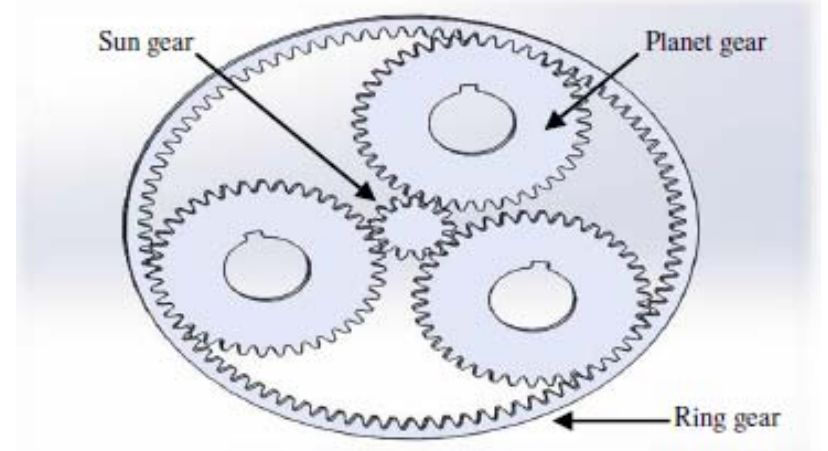

FIGURE I. PLANETARY GEAR MODEL WITH THREE PLANET GEARS

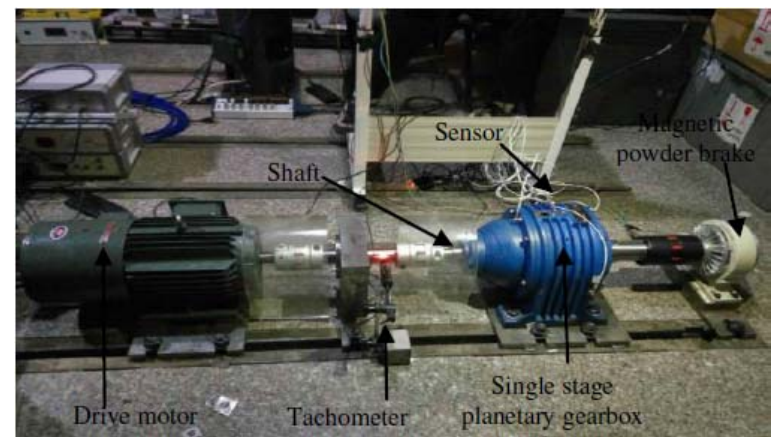

FIGURE II. TEST RIG OF A SINGLE STAGE PLANETARY GEARBOX

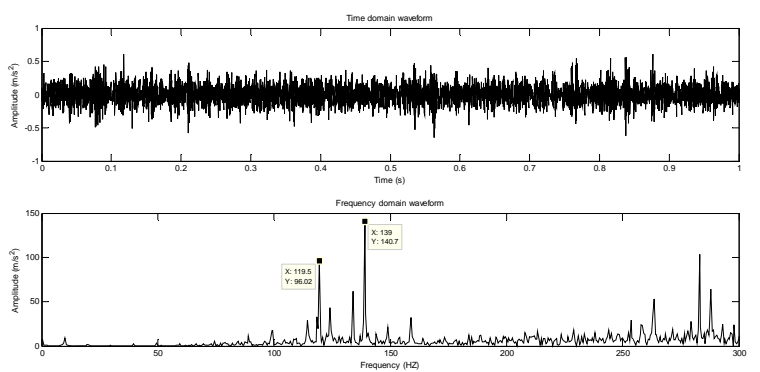

FIGURE III. TIME DOMAIN WAVEFORM AND ITS FREQUENCY

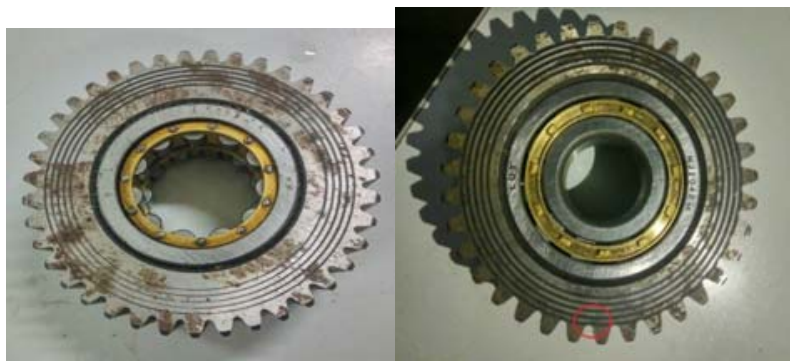

(A)

(B)

FIGURE IV. THE NORMAL PLANET GEAR AND DAMAGE GEAR (A) NORMAL GEAR; (B) ARTIFICIALLY SEEDED DAMAGE GEAR

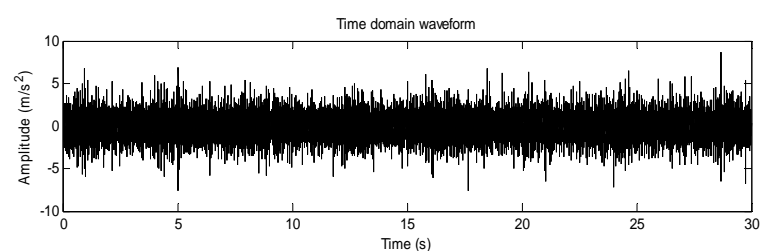

(A)

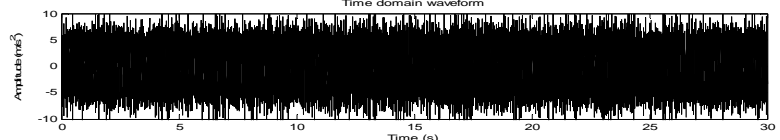

(B)

FIGURE V. TIME-DOMAIN WAVEFORM (A) NORMAL GEAR; (B) DAMAGE GEAR

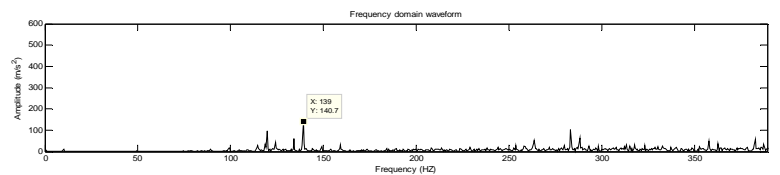

(A)

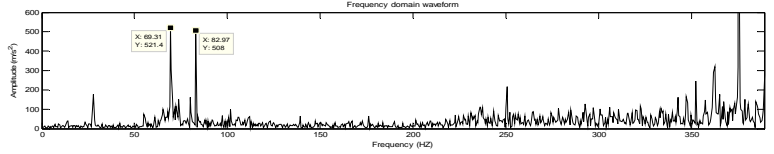

(B)

FIGURE VI. FREQUENCY DOMAIN WAVEFORM (A) NORMAL GEAR; (B) DAMAGE GEAR 